\title{
O Estado e os Serviços Públicos
}

\section{ALCÂNTARA NOGUEIRA}

A través dos séculos para explicar a formação e o desenvolvimento do Estado, bem como determinar seus elementos, diversas têm sido as teorias formuladas pelos filósofos do Direito. No que concerne a êsses elementos constitutivos do Estado, encontra-se em plano destacado a soberania que, para um grande número de juristas, antigos e modernos. é o principal.

Dêsse modo, tem sido a soberania considerada o poder absoluto do Estado (BoDIN), ou a sua própria vontade, isto é, por esta é que o Estado se obriga jurìdicamente (JELLINEK).

Destaca-se o direito francês, por exemplo, que considera a soberania como "o poder de comando do Estado" ou a "vontade da Nação", ou ainda como diria Esmein, uma soberania interna - "direito de dar ordens a todos os indivíduos que compõem uma Nação e aos que residem no território nacional", e uma soberania externa - "direito de representar a Nação e de estabelecer relações com as outras nações".

Contra essas idéias se insurgiu uma das figuras mais vigorosas e discutidas do direito público moderno, que é LEON DUGUTT. Logo de início, êle nega êsse poder de comando, a soberania, pois ensina que o Estado não possui personalidade jurídica, para chegar ao extremo de negar a sua própria existência, pressupondo-a, embora, depois, porque do contrário não poderia escrever o seu tratado de Direito Constitucional. (2)

Sem dúvida, repelindo a noção de soberania. Duguit sente-se obrigado a apresentar para esta um substitutivo. Êsse novo elemento do Estado é o serviço público, pois aquêle, no seu pensar "não é como se quis que êle fôsse e como se julgou durante algum tempo que poderia ser, um poder que manda, uma soberania; é uma cooperação de serviços públicos organizados e fiscalizados pelos governantes". (3) Enfim, num âmbito mais geral, o próprio direito público moderno, para o grande jurista, gravita em tôrno da noção de serviço público.

Ora, que se considere a serviço público uma espécie de motor em ação para fazer realizar inúmeras atribuições do Estado - interna e externamente, - compreende-se perfeitamente; mas disso a confundir o próprio serviço público com o poder do Estado, quer dizer, com suas diferentes atividades de mando, vai uma distância quase inatingível e uma pretensão extremamente audaciosa, para não dizer de dificílima demonstração. 
Isso é tanto mais verdadeiro, quando se pode afirmar que não existe a menor contradição em considerar o Estado sujeito de um poder de mando e admitir, igualmente, a existência de um mecanismo que realize tôda sorte de atividades pertinentes àquele poder de mandar. Este, quando dirigido pela regra de Direito, é, por natureza, superior e anterior a qualquer modalidade de serviço público que, por seu turno, servirá, como não se pode duvidar, sob ponto de vista objetivo, para se entender, pròpriamente, êsse poder de mando, em diversos setores de sua atividade.

DUGUIT, entretanto, colocando-se de modo visível numa situação unilateral, é levado a desconhecer essa duplicidade de asppecto no Estado, isto é, a considerar que o poder de fato exercido pelos governantes, para ser legítimo, deve ser um poder de direito, sendo que êsse poder de direito tanto mais será legítimo quanto mais êle traduza a vontade da maioria e não o poder de direito imposto pela minoria que dirige aquela em nome de um certo direito, que é o seu direito; e também, por fôrça dêste, exercem-se as funções públicas que, mesmo sendo deveres do Estado, não devem ser concedidas como sendo o único poder estatal.

Êsse exagêro quase que anula a verdadeira personalidade jurídica do Estado, porque só reconhece o poder sendo exercido diretamente pelos dirigentes, esmagando aquêle sentido de direito que, na ordem social. deve servir de traço de concórdia entre governantes e governados.

Afirma Dugurt, embora sem indicar as razões dessa interferência do Estado que, "à medida que a civilização progride, a intervenção dos governantes torna-se normalmente mais freqüente, porque só ela pode fomentar a civilização" (4). De fato, a medida valorativa dessa intervenção deve ser o interêsse social evitando, na prática, a exploração de um indivíduo por outro. E é só nesse aspecto que se pode falar em progresso social.

Muitas nações têm experimentado essa intervenção, sem essa característica social, especialmente no plano econômico; e o resultado é que o que houve foi a reunião de um grupo de privilegiados a imporem certos direitos que não são os direitos da maioria a imposição de uma ordem baseada em místicas apresentadas como forma de patriotismo salvador ou superioridade de raça ou cultura. Assim procederam a Alemanha nazista e a Itália fascista.

Dentro dêsse pressuposto é que poderá ter validade o que afirma DuGuIT, ao declarar que o serviço público é o "fundamento e o limite do poder do govêrno" ou "tôda atividade cuja realização deve ser regulada, assegurada e fiscalizada pelos governantes, porque a realização dessa atividade é indispensável ao desenvolvimento da interdependência social, e porque é de tal natureza que só pode ser assegurada pela intervenção da fôrça do govêrno". O ilustre jurista não diz que tipo de govêrno é êsse, que ordem social é a que êle representa. E' o govêrno apenas, o que detém o poder considerado legìtimamente organizado. mesmo que seja o da minoria, representando uma classe que chegou ao poder não pela vontade da maioria, e que assim não pode representar os interêsses desta.

Sem dúvida, o Estado é o criador e mantenedor de uma organização de serviços que, sob a orientação de meios jurídicos, se realiza no meio social, 
coativamente. Mas isso não deve levar à exagerada concepção de que tôdas as atividades devam ser consideradas serviços públicos, pelo simples fato de estarem relacionadas ao Estado, dessa ou daquela forma. Idéias dessa natureza geram o Estado com roupagem de prepotência, sem representar os verdadeiros interêsses da maioria que são os únicos a deverem ser impostos, porque representam a própria classe no poder.

Êsse ponto de vista, defende-o outro grande jurista, BIELSA, para quem - serviço público é, não sòmente a atividade pública mas também a privada, desde que esteja regulada por lei e tenha como finalidade específica a satisfação mais ou menos ininterrupta das chamadas necessidades sociais.

E' comum considerar-se que os poderes do Estado devem ter certa limitação desde que firam as normas jurídicas; assim como, deve haver uma divisão no que concerne ao domínio em que se exercitam aquêles poderes e essas normas, embora exista entre êles uma interdependência. Mas o que se deve considerar é que existem verdadeiras categorias de serviços públicos e, como tal, só poderão assim ser admitidos, quando possuem determinada atribuição no campo administrativo pròpriamente dito. Porquanto. fora daí, a rigor, no sentido técnico, não existe uma função pública, mas uma ordem de atribuições que, mesmo sendo de interêsse coletivo, deve ser definida como constituindo funções gerais que não se prendem à orientação imediata do Estado. Têm dêste, naturalmente, a assistência de tôda e qualquer atividade que vise à realização das finalidades da ordem civil, para com a coletividade; e é nesse sentido que se deve compreender como necessária a interferência do Estado porque isso será impedir a liberdade licenciosa que caracteriza o liberalismo, especialmente no âmbito das atividades econômicas, onde essa liberdade é tão solicitada.

Reconhecendo talvez essa necessidade de evitar os excessos, BONNARD admite, baseado no princípio de separação dos poderes, a existência de três modalidades de serviços: legislativo, administrativo, e jurisdicional. No primeiro, que é o legiferante, sua atividade faz-se indistintamente para "tôdas as intervenções e atribuições do Estado"; no segundo, via de regra, sua competência refere-se a tôda sorte de atribuições do Estado; no terceiro, como no legislativo não há "especialização por função".

Daí, pode-se deduzir que, quando se trata de legislar ou fazer a aplicação do Direito, não há nos casos mais gerais uma atribuição para que se dê essa realização específica do Estado. São, portanto, funções de caráter geral. Pelo contrário, já na esfera administrativa essas funções. ou melhor dito, cada serviço público tem a sua correspondência obrigatória numa atribuição especificada pelo Estado.

Acresce, ainda, que os serviços públicos têm certas características espcciais, não se podendo confundir com outras atividades do Estado que pertencem àquela categoria já mencionada, isto é, funções gerais, ou outras exercidas mesmo por particulares e que tratem de interêsses coletivos. Sem levar em conta essas peculiaridades, que são, aliás, importantes, devem ser enumeradas estas outras: - execução direta feita pelo Estado, ou por êle concedida, objetivando necessidades coletivas, e as ressaltadas por autores como 
MOSHER e KINGSLEY : urgência na sua execução, independência quanto à questão de preços no seu suprimento, uma vez que não se regulam aquêles pelo preço do mercado; sua qualidade fundamental de mono ou semimonopolística, e, por fim, sempre provido por lei. (7)

O Estado moderno é, de fato, cada vez mais intervencionista, especialmente no que concerne às atividades econômicas, já que a liberdade individual nesse setor é, via de regra. forma de escravidão para a maioria que trabalha. Mas não é possível, como faz Duguit, considerar os serviços públicos como substitutivo da soberania do Estado.

\section{BIBLIOGRAFIA}

(1) ESMEIN - Droit Constitutionne1.

(2) Sôbre o assunto, nosso artigo na revista "Direito", vol. XXXI, Rio, 45 - Direito e Estado.

(3) LeON Duguit - Manuel de Droit Constituitionnel.

(4) ib., op. cit.

(5) Rafael Bielsa - Derecho Administrativo.

(6) ROger BONNARd - Précis de Droit Administratif.

(7) William E. Mosher and J. Donald Kingsley - Public Personnel Administration.

\section{SUMMARY}

1. Sovereignty as an element of the State. The idea of sovereignty according to Bodin, Jellinek and Esmein.

2. Duguit and his criticism of the concept of sovercignty. Public service to replace sovereignty. The State as a corporation of public services organized and supervised by glovernment agents.

3. A criticism of the confusion between public service and the power of the State. The State and his power, side by side with the agencies through which the activities pertinent to that power are carried out. The unilateralism of Duguit denies such duality.

4. The interference of the government is the greater the more civilization progresses. The Nazi experience and the Fascist patterns as examples of an interference contrary to the social interests. Within such proviso it is valid the statement (Duguit's) that public service is the "basis and the limits" of the power of the government.

5. All activities related to the State are public services. Moreover, not anly public acticities but also private ones are public services, provided they are regulated by law and have as their specific objective the satisfaction of social necessities (Bielsa).

6. The three kinds of service, according to Bonnard: legislative, administrative and jurisdictional. Distinctions shown by each one. Corollaries of such distinctions.

7. Special characteristics of public services, which distinguish them from general functions and others exercised by private persons although dealing with social interests.

8. The modern State interferes every day more with social life, particularly in the field of economics. It is not licit, however, to consider the public services as a substitute for the sovereignty of the State. 